\title{
Digital gene expression analysis in mice lung with coinfection of influenza and streptococcus pneumoniae
}

\author{
Jun Luo ${ }^{1}$, Linlin Zhou ${ }^{1}$, Hongren Wang ${ }^{1}$, Zhen Qin ${ }^{1}$, Li Xiang1, Jie Zhu' ${ }^{2}$, Xiaojun \\ Huang ${ }^{1}$, Yuan Yang ${ }^{1}$, Wanyi Li ${ }^{1}$, Baoning Wang ${ }^{1}$ and Mingyuan $\mathbf{L i}^{1,3}$ \\ ${ }^{1}$ Department of Microbiology, West China School of Basic Medical Sciences and Forensic Medicine, Sichuan University, \\ Chengdu 610041, China \\ ${ }^{2}$ Department of Microbiology, Guizhou Medical University, Guiyang 550004, China \\ ${ }^{3}$ State Key Laboratory of Oral Diseases, Sichuan University, Chengdu, Sichuan 610041, China \\ Correspondence to: Mingyuan Li, email: Mingyuanli1704@foxmail.com \\ Baoning Wang, email: Pinheng9@163.com \\ Keywords: influenza A virus; streptococcus pneumoniae; digital gene expression; apoptosis \\ Received: May 02, $2017 \quad$ Accepted: November 26, 2017 Published: December 11, 2017 \\ Copyright: Luo et al. This is an open-access article distributed under the terms of the Creative Commons Attribution License 3.0 \\ (CC BY 3.0), which permits unrestricted use, distribution, and reproduction in any medium, provided the original author and source \\ are credited.
}

\section{ABSTRACT}

Influenza A virus (IAV) and Streptococcus pneumoniae (SP) are two major upper respiratory tract pathogens that can also cause infection in polarized bronchial epithelial cells to exacerbate disease in coinfected individuals which may result in significant morbidity. However, the underlying molecular mechanism is poorly understood. Here, we employed BALB/C ByJ mice inflected with SP, IAV, IAV followed by SP (IAV+SP) and PBS (Control) as models to survey the global gene expression using digital gene expression (DGE) profiling. We attempt to gain insights into the underlying genetic basis of this synergy at the expression level. Gene expression profiles were obtain using the Illimina/Hisseq sequencing technique, and further analyzed by enrichment analysis of Gene Ontology (GO) and Pathway function. The hematoxylin-eosin (HE) staining revealed different tissue changes in groups during which IAV+SP group showed the most severe cell apoptosis. Compared with Control, a total of 2731, 3221 and 3946 differentially expressed genes (DEGs) were detected in SP, IAV and IAV+SP respectively. Besides, sixty-two GO terms were identified by Gene Ontology functional enrichment analysis, such as cell killing, biological regulation, response to stimulus, signaling, biological adhesion, enzyme regulator activity, receptor regulator activity and translation regulator activity. Pathway significant enrichment analysis indicated the dysregulation of multiple pathways, including apoptosis pathway. Among these, five selected genes were further verified by quantitative reverse transcriptionpolymerase chain reaction (qRT-PCR). This study shows that infection with SP, IAV or IAV+SP induces apoptosis with different degrees which might provide insights into the molecular mechanisms to facilitate further research.

\section{INTRODUCTION}

Secondary bacterial pneumonia is an important complication responsible for illness and death during epidemic and pandemic influenza [1]. A number of causative bacteria have been described in patients, including Staphylococcus aureus and Haemophilus influenza, but $\mathrm{SP}$ is the most common pathogen, and over $50 \%$ of the deaths have been attributed to secondary pneumococcal pneumonia following primary influenza virus infection [2]. The highly variable IAV evolve rapidly and cause epidemics and pandemic of acute respiratory disease that are often characterized by high morbidity and mortality in humans [3]. Secondary SP infections increase the severity and lethality in influenza virus-infected humans based on co-pathogenesis of both pathogens, also called lethal 
synergismas reviewed recently [4]. Analysis of the host response in the lungs of mice during 1918 virus infection revealed dramatically alveolar epithelial damage and persisted unabated until death [5]. Similar studies in ferrets and cynomolgus macaques demonstrated that the 1918 virus was highly lethal in both species and with severe lung pathology similar to that seen in mice $[6,7]$. These studies revealed that the reconstructed 1918 pandemic influenza virus was highly pathogenic in several animal models.

Secondary bacterial pneumonia is still a significant cause of morbidity and mortality in years where the viruses are not virulent enough to cause severe lung damage or death from the virus alone [8-10]. However, the possible mechanisms of underlying the association between influenza and the following pneumococcal infections are still unclear, exploration for the underlying mechanisms would be a research priority because of their potentially important implications for prevention and control.

Recent studies have reported some genes might relate to cell apoptosis after coinfected with virus and bacteria, however, to the best of our knowledge, no study has been reported on the coinfection of SP and IAV in a comprehensive genetic view.

The digital gene expression (DGE) system is always used to do the comparative gene expression research which is a tag-based transcriptome sequencing approach. When using DGE, clean reads with certain end nuclease were strained through raw reads, and then mapped to the corresponding reference database. The quantity of each mRNA yielded from each gene are defined by the expression degree of the actual total genes in each sample [11]. In our study, we conducted a massive analysis of gene expression changes by using DGE when mice were infected with SP, IAV or IAV+SP, to better understand how the coinfection caused high morbidity and mortality in mice.

\section{OBJECTIVE}

The objective of this study is to construct mice model of the coinfection of IAV+SP and to apply high throughput sequencing method to acquire gene expression changes of transcriptome in mice lung tissues infecting with IAV and secondary SP, which helps to perfect the molecular mechanism of the coinfection and provides research clues and ideas to further clarify the mechanism of the coinfection.

\section{RESULTS}

\section{Lethal synergism}

Mice infected with either SP or IAV alone exhibited mortality rates of $20 \%$ and $35 \%$, respectively. All mice infected with IAV + SP succumbed to infection in $<48 \mathrm{~h}$ $(P<0.0001$, for difference in survival, vs. all other groups), demonstrating that synergistic mortality occurs in the model (Figure 1). Lung tissues in mice were analyzed by hematoxylin-eosin (HE) staining. Normal lung tissues could be observed in mice from control (Figure 2A). For tissues from IAV+SP group, severely adverse histopathology changes were observed which revealed large amount of infiltrated inflammatory cell, consolidations of lung tissue, and disappearances of pulmonary alveoli (Figure 2B). While histopathology lung tissues from IAV and SP groups showed moderately (Figure 2C) and mildly (Figure 2D) adverse changes, respectively. Titers of SP or IAV in lung tissues was measured after infection. Titer of SP from IAV+SP group was found to be significantly higher than that from SP group after 48 hours of infection (Figure 3A). Titer of IAV in IAV group reached a peak in five days of infection, but dramatically increased IAV titer could be observed once infected with SP afterwards (Figure 3B).

\section{Analysis of DGE libraries}

A total of twelve RNA samples, generated from three biological replicates under the four treatments were subjected to Using Illumina Hiseq2500 sequencing (Table 1). Approximately 11.4-13.4 million raw reads were sequenced per sample. After filtering out low-quality data (reads containing unknown base $\mathrm{N}$ and only adaptor reads), approximately $11.0-13.0$ million clean reads remained in each library. The Q30 values (sequencing error rate, $0.1 \%$ ) were more than $93.04 \%$, and the GC percentages were between $52.89-53.11 \%$. Approximately $87.96-91.06 \%$ reads in the twelve DGE libraries were unique mapped reads, suggesting that the profiling was reliable. To evaluate the reproducibility of DEG library sequencing, a Pearson correlation analysis was performed for every three replicates. The square of the Pearson correlation coefficient $\left(r^{2}\right)$ was greater than 0.94, indicating both operational stability and the reliability of the experimental results (Figure 4). For Control vs SP, Control vs IAV and Control vs IAV+SP, the Pearson correlation coefficient was $0.822,0.795,0.711$, respectively, suggesting that the $\mathrm{SP}+\mathrm{IAV}$ induced the most changes of gene expression profile which should be related to the pathogenesis of mice lung tissue (Figure 5).

\section{Analysis of GO and KEGG pathways}

Results showed that 2731, 3221, 3946 DEGs were detected in Control vs SP, Control vs IAV and Control vs SP+IAV comparisons respectively, of which, 1402, 1588 and 1874 were up-regulated and 1329, 1633 and 2072 were down-regulated in the three comparisons (Figure 6).

To understand their functions, all the DEGs were mapped to terms of GO database, and then the DEGs were compared with the whole reference database. There are three ontologies in GO database, namely, molecular function, cellular component and biological process 


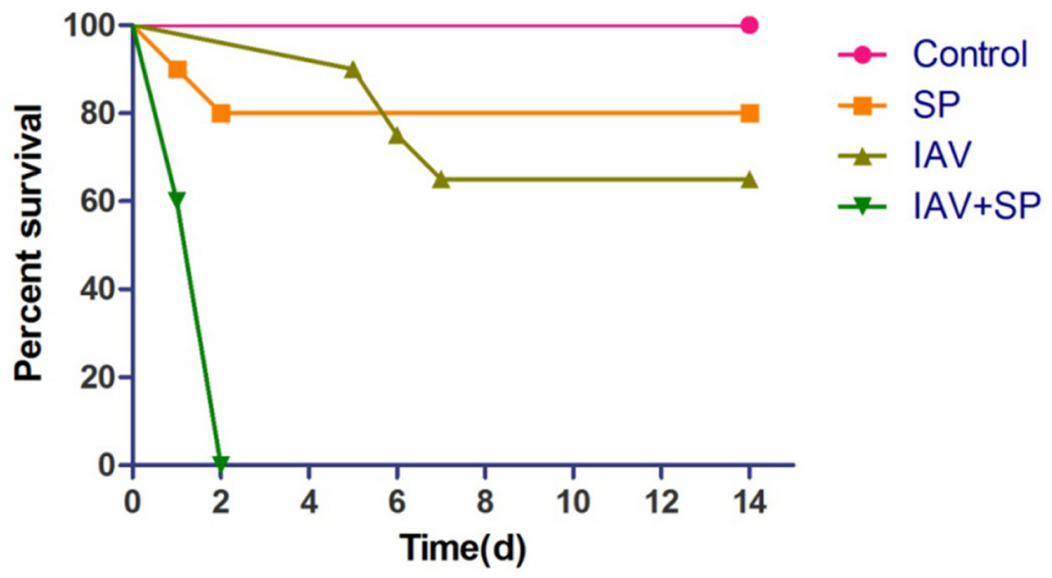

Figure 1: Synergistic mortality. Groups of mice $(n=20)$ were infected with either SP, IAV or IAV+SP.
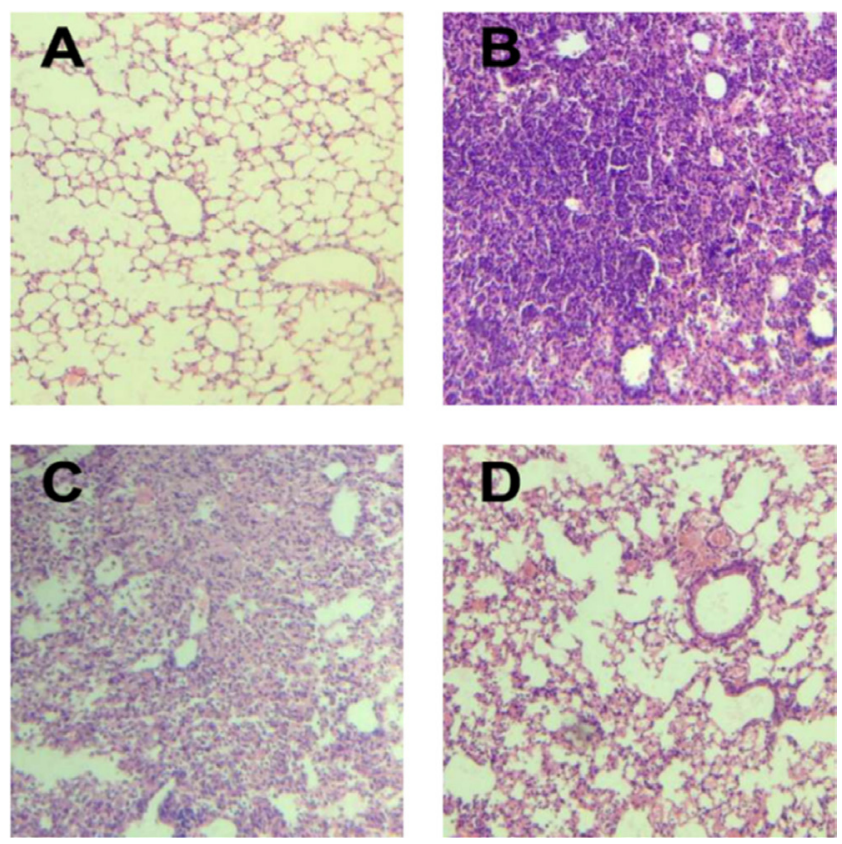

Figure 2: Histopathological changes in lung tissues with HE staining (100 $\times$ magnification). (A) HE staining of lung tissue in control group; (B) HE staining of lung tissue in IAV+SP group; (C) HE staining of lung tissue in IAV group; (D) HE staining of lung tissue in SP group; HE: hematoxylin-eosin; IAV: Influenza A virus; SP: Streptococcus pneumoniae.
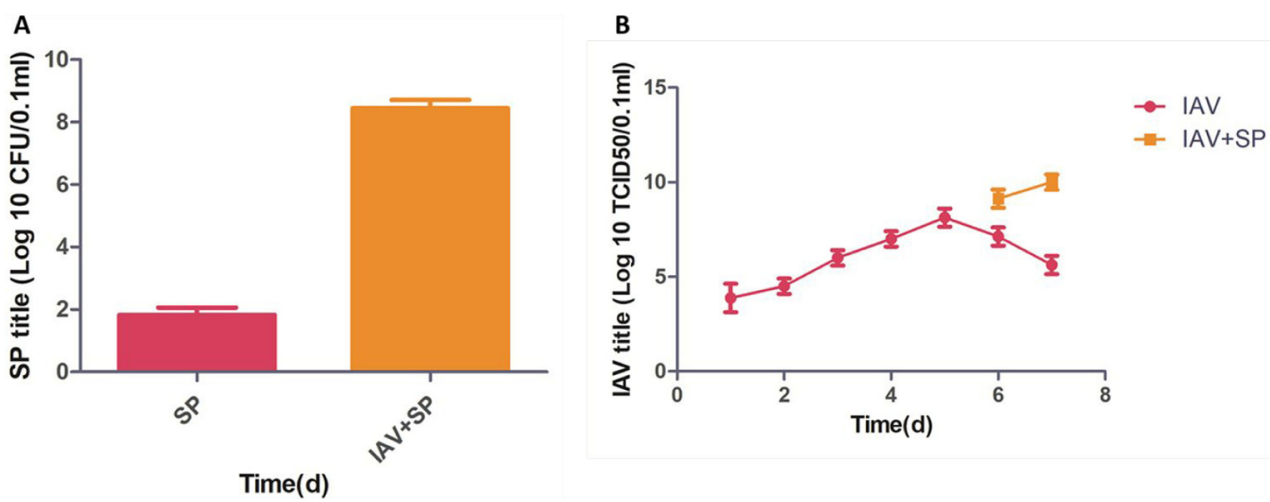

Figure 3: Titer changes after infections of SP, IAV and IAV+SP (A-B). 
Table 1: Summary for DGE sequencing dataset

\begin{tabular}{|c|c|c|c|c|c|c|c|c|c|c|}
\hline $\begin{array}{l}\text { Sample } \\
\text { name }\end{array}$ & $\begin{array}{l}\text { Raw } \\
\text { reads }\end{array}$ & Clean reads & Total bases & $\begin{array}{l}\text { Mapped } \\
\text { reads }\end{array}$ & $\begin{array}{l}\text { Uniq mapped } \\
\text { reads }\end{array}$ & $\begin{array}{c}\text { Multiple } \\
\text { Map reads }\end{array}$ & $\begin{array}{c}\text { Reads map } \\
\text { to ' }+ \text { ' }\end{array}$ & Reads map to '-' & GC content & $\% \geq Q 30$ \\
\hline Control_1 & $13,436,180$ & 13059967 & 665976339 & $\begin{array}{c}12,245,594 \\
(93.76 \%)\end{array}$ & $\begin{array}{c}11,892,783 \\
(91.06 \%)\end{array}$ & $\begin{array}{l}352,811 \\
(2.70 \%)\end{array}$ & $\begin{array}{c}6,051,986 \\
(46.34 \%)\end{array}$ & $\begin{array}{l}6,067,065 \\
(46.46 \%)\end{array}$ & $53.05 \%$ & 0.94 \\
\hline Control_2 & 11652141 & 11346855 & 578615876 & $\begin{array}{c}10,620,247 \\
(93.60 \%)\end{array}$ & $\begin{array}{c}10,294,003 \\
(90.72 \%)\end{array}$ & $\begin{array}{l}326,244 \\
(2.88 \%)\end{array}$ & $\begin{array}{c}5,244,975 \\
(46.22 \%)\end{array}$ & $\begin{array}{c}5,250,388 \\
(46.27 \%)\end{array}$ & $53.11 \%$ & 0.94 \\
\hline Control_3 & 12573873 & 12182826 & 621246811 & $\begin{array}{c}11,369,053 \\
(93.32 \%)\end{array}$ & $\begin{array}{c}11,018,016 \\
(90.44 \%)\end{array}$ & $\begin{array}{l}351,037 \\
(2.88 \%)\end{array}$ & $\begin{array}{c}5,613,900 \\
(46.08 \%)\end{array}$ & $\begin{array}{c}5,622,666 \\
(46.15 \%)\end{array}$ & $52.89 \%$ & 0.93 \\
\hline SP_1 & 12210156 & 11843851 & 603959314 & $\begin{array}{c}11,018,282 \\
(93.03 \%)\end{array}$ & $\begin{array}{c}10,619,693 \\
(89.66 \%)\end{array}$ & $\begin{array}{l}398,589 \\
(3.37 \%)\end{array}$ & $\begin{array}{c}5,421,665 \\
(45.78 \%)\end{array}$ & $\begin{array}{l}5,436,527 \\
(45.90 \%)\end{array}$ & $52.95 \%$ & 0.94 \\
\hline SP_2 & 12025104 & 11670363 & 595113122 & $\begin{array}{c}10,801,886 \\
(92.56 \%)\end{array}$ & $\begin{array}{c}10,410,413 \\
(89.20 \%)\end{array}$ & $\begin{array}{l}391,473 \\
(3.35 \%)\end{array}$ & $\begin{array}{c}5,310,270 \\
(45.50 \%)\end{array}$ & $\begin{array}{l}5,326,496 \\
(45.64 \%)\end{array}$ & $53.02 \%$ & 0.94 \\
\hline SP_3 & 11769692 & 11418955 & 582292359 & $\begin{array}{c}10,583,344 \\
(92.68 \%)\end{array}$ & $\begin{array}{c}10,215,301 \\
(89.46 \%)\end{array}$ & $\begin{array}{l}368,043 \\
(3.22 \%)\end{array}$ & $\begin{array}{l}5,206,586 \\
(45.60 \%)\end{array}$ & $\begin{array}{l}5,220,412 \\
(45.72 \%)\end{array}$ & $52.91 \%$ & 0.93 \\
\hline IAV_1 & 12696076 & 12297419 & 627087395 & $\begin{array}{c}11,358,377 \\
(92.36 \%)\end{array}$ & $\begin{array}{c}10,984,142 \\
(89.32 \%)\end{array}$ & $\begin{array}{l}374,235 \\
(3.04 \%)\end{array}$ & $\begin{array}{l}5,601,490 \\
(45.55 \%)\end{array}$ & $\begin{array}{l}5,614,813 \\
(45.66 \%)\end{array}$ & $52.91 \%$ & 0.94 \\
\hline IAV_2 & 13262578 & 12866027 & 656082743 & $\begin{array}{c}11,789,646 \\
(91.63 \%)\end{array}$ & $\begin{array}{c}11,317,209 \\
(87.96 \%)\end{array}$ & $\begin{array}{l}472,437 \\
(3.67 \%)\end{array}$ & $\begin{array}{l}5,776,515 \\
(44.90 \%)\end{array}$ & $\begin{array}{l}5,804,632 \\
(45.12 \%)\end{array}$ & $53.11 \%$ & 0.93 \\
\hline IAV_3 & 13396497 & 12983885 & 662092858 & $\begin{array}{c}12,094,096 \\
(93.15 \%)\end{array}$ & $\begin{array}{c}11,705,196 \\
(90.15 \%)\end{array}$ & $\begin{array}{l}388,900 \\
(3.00 \%)\end{array}$ & $\begin{array}{c}5,966,244 \\
(45.95 \%)\end{array}$ & $\begin{array}{c}5,978,450 \\
(46.05 \%)\end{array}$ & $52.97 \%$ & 0.94 \\
\hline $\mathrm{SP}+\mathrm{IAV} \_1$ & 12582446 & 12188615 & 621537587 & $\begin{array}{c}11,205,000 \\
(91.93 \%)\end{array}$ & $\begin{array}{c}10,783,215 \\
(88.47 \%)\end{array}$ & $\begin{array}{l}421,785 \\
(3.46 \%)\end{array}$ & $\begin{array}{l}5,505,381 \\
(45.17 \%)\end{array}$ & $\begin{array}{c}5,529,443 \\
(45.37 \%)\end{array}$ & $53.10 \%$ & 0.93 \\
\hline SP+IAV_2 & 11428961 & 11080378 & 565024547 & $\begin{array}{c}10,234,359 \\
(92.36 \%)\end{array}$ & $\begin{array}{l}9,851,073 \\
(88.91 \%)\end{array}$ & $\begin{array}{l}383,286 \\
(3.46 \%)\end{array}$ & $\begin{array}{l}5,035,079 \\
(45.44 \%)\end{array}$ & $\begin{array}{l}5,045,563 \\
(45.54 \%)\end{array}$ & $52.91 \%$ & 0.93 \\
\hline $\mathrm{SP}+\mathrm{IAV} \_3$ & 12423682 & 12016185 & 612745601 & $\begin{array}{c}11,039,713 \\
(91.87 \%)\end{array}$ & $\begin{array}{c}10,626,010 \\
(88.43 \%)\end{array}$ & $\begin{array}{l}413,703 \\
(3.44 \%)\end{array}$ & $\begin{array}{l}5,425,391 \\
(45.15 \%)\end{array}$ & $\begin{array}{c}5,444,278 \\
(45.31 \%)\end{array}$ & $53.10 \%$ & 0.94 \\
\hline
\end{tabular}

which are further subdivided into 62 subcategories in our study. The biological process contains 22 categories, cellular component contains 19 categories and molecular function contains 21 categories. The subcategory at the "cell part," "cell," "cellular process," "single-organism process," "binding," "biological regulation," "organelle, "“membrane," "response to stimulus," and "catalytic activity" included the highest number of DEGs relative to other subcategories and IAV+SP contained the most DEGs than the other groups. In the three categories, "biological process" is dominant compared to cellular processes and metabolic processes (Figure 7).

To further understand biological functions of the identified genes and classify their functional annotation, the significantly enriched pathways were identified by comparing them to the KEGG database (Figure 8). When comparing Control vs SP, 946 DEGs were annotated to 206 metabolic pathways. Among these pathways, the "Cytokine-cytokine receptor interaction" included the most DEGs (85, ko04060), followed by the "Pathways in cancer" (67, ko05200), "Phagosome" (53, ko04145), "Cell adhesion molecules" (51, ko04514) and "Chemokine signaling pathway" (50, ko04062) etc. The comparison of Control vs IAV was annotated 1089 DEGs to 211 pathways. Most of these DEGs were clustered in the "Cytokine-cytokine receptor interaction" category (98), followed by the "Pathways in cancer" (69), "Phagosome" (63), "Cell adhesion molecules" (62) and "Chemokine signaling pathway" (59) etc. As to Control vs IAV+SP,
1329 DEGs were annotated to 219 pathways. "Cytokinecytokine receptor interaction" (105) was also annotated the most DEGs, then "Pathways in cancer" (92), "MAPK signaling pathway" (67, ko04010), "Phagosome" (65) and "Chemokine signaling pathway" (62) etc. Some pathways closely related to infection-induced damage were significantly enriched, such as the "apoptosis", which warranted to be further study. As shown in Figure 9, some genes which closely related to apoptosis revealed remarkable high expression level in SP+IAV group.

\section{Identification and verification of DEGs}

To validate the expression profiles obtained by RNA-Seq, qRT-PCR was performed on five genes selected at random with high or low expression levels. Expression comparisons were performed between SP and Control, IAV and Control, IAV+SP and Control by qRT-PCR. For all of the genes, the trend in qRT-PCR expression was in agreement with the RNA-Seq data, with only some foldchange discrepancies. This result was consistent with the DGE result, which were considered to be of very high reliability (Figure 10).

\section{DISCUSSION}

It is well known that pneumococcal pneumonia often occurs following primary influenza infection, and secondary pneumococcal pneumonia complicates many severe cases in 

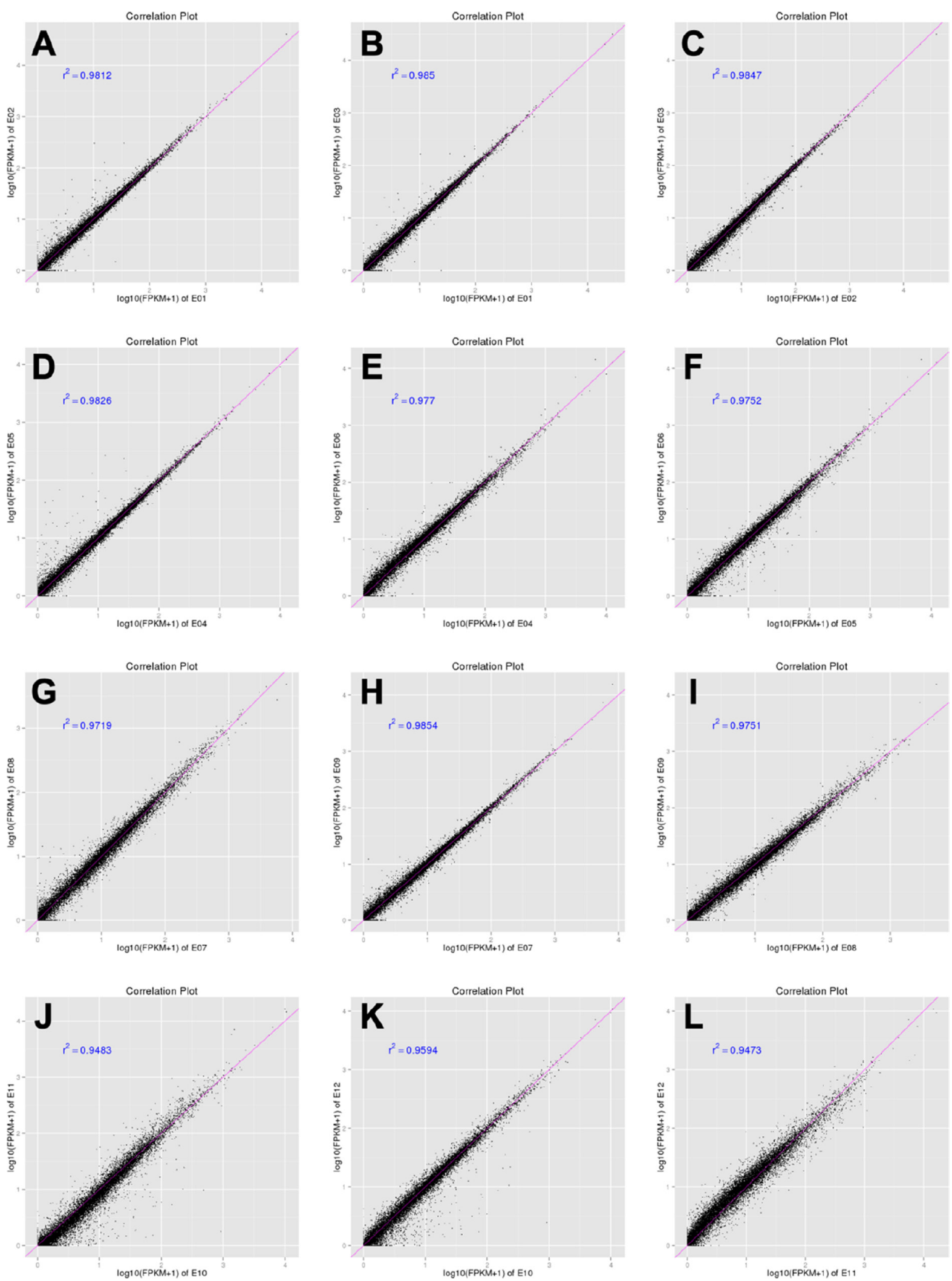

Figure 4: Correlation tests for the replicates. The abscissa represents the value $\log 10(\mathrm{FPKM}+1)$ of one duplicate; the ordinate represents the value $\log 10(\mathrm{FPKM}+1)$ of the other duplicate. $\mathrm{r}^{2}$ is the square of Pearson Correlation Coefficient. E01,E02,E03 represent the three biological replicates of Control (A, B, C); E04,E05,E06 represent the three biological replicates of SP (D, E, F); E07,E08,E09 represent the three biological replicates of IAV $(\mathbf{G}, \mathbf{H}, \mathbf{I})$; E01,E02, E03 represent the three biological replicates of IAV+SP $(\mathbf{J}, \mathbf{K}, \mathbf{L})$. 
influenza-infected hosts $[1,12]$. Several mechanisms have been suggested to explain the enhanced susceptibility to secondary pneumococcal infections after primary influenza infection. Studies have considered that influenza-mediated lung damage contributed to enhanced susceptibility to secondary bacterial infections [13, 14]. Previous studies showed that apoptosis played a role in influenza virus pathogenesis and in causing cell death and tissue damage during numerous pathogenic responses [15-17].

Transduction pathways play crucial roles in the development of infection, participating in key steps in multiple pathways that link extracellular stimuli to intracellular signals [18]. In this study, the apoptosis pathway was significantly differentially activated in particular, which directed and integrated a complex network that was involved in activation of kinases, thereby controlling cell apoptosis and leading lung tissue damage
(Figure 11). Alveolar epithelial apoptosis was described as a common feature of acute lung injury caused by direct or indirect factors such as pneumonia, aspiration, sepsis, or trauma [19, 20]. Apoptosis was described to occur in the lungs of patients with acute lung injury [21, 22]. Apoptosis is a regulated form of cell death that induced in several ways, including the death receptor pathway, the mitochondrial pathway, and ER stress-mediated apoptosis [23, 24]. Apoptosis pathway was significantly up-regulated in mice lung due to the infection. In death receptor pathway, upon exogenous apoptotic stimulation, extracellular signals were transmitted into cells through the cell membrane death receptor Fas (fold change of Fas : $\mathrm{SP}=1.64, \mathrm{IAV}=2.00, \mathrm{IAV}+\mathrm{SP}=4.25)$, which then mediated apoptosis through caspase- 8 with subsequent cleavage of procaspase- 3 and resulting apoptosis [25]. Caspase- 8 was activated and promoted cell apoptosis through
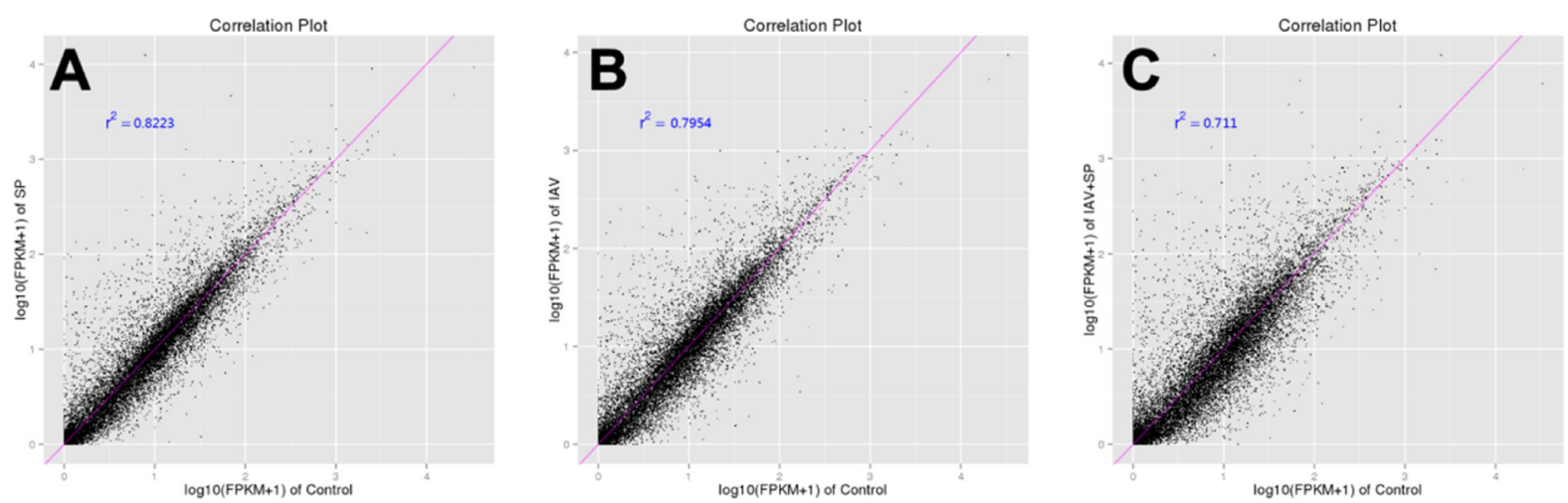

Figure 5: Correlation tests for groups of different treatments. The abscissa represents the value $\log 10$ (FPKM + 1) of one group; the ordinate represents the value $\log 10(\mathrm{FPKM}+1)$ of the other group. $r^{2}$ is the square of Pearson Correlation Coefficient. (A) Control VS SP; (B) Control VS IAV; (C) Control VS IAV+SP.

2500

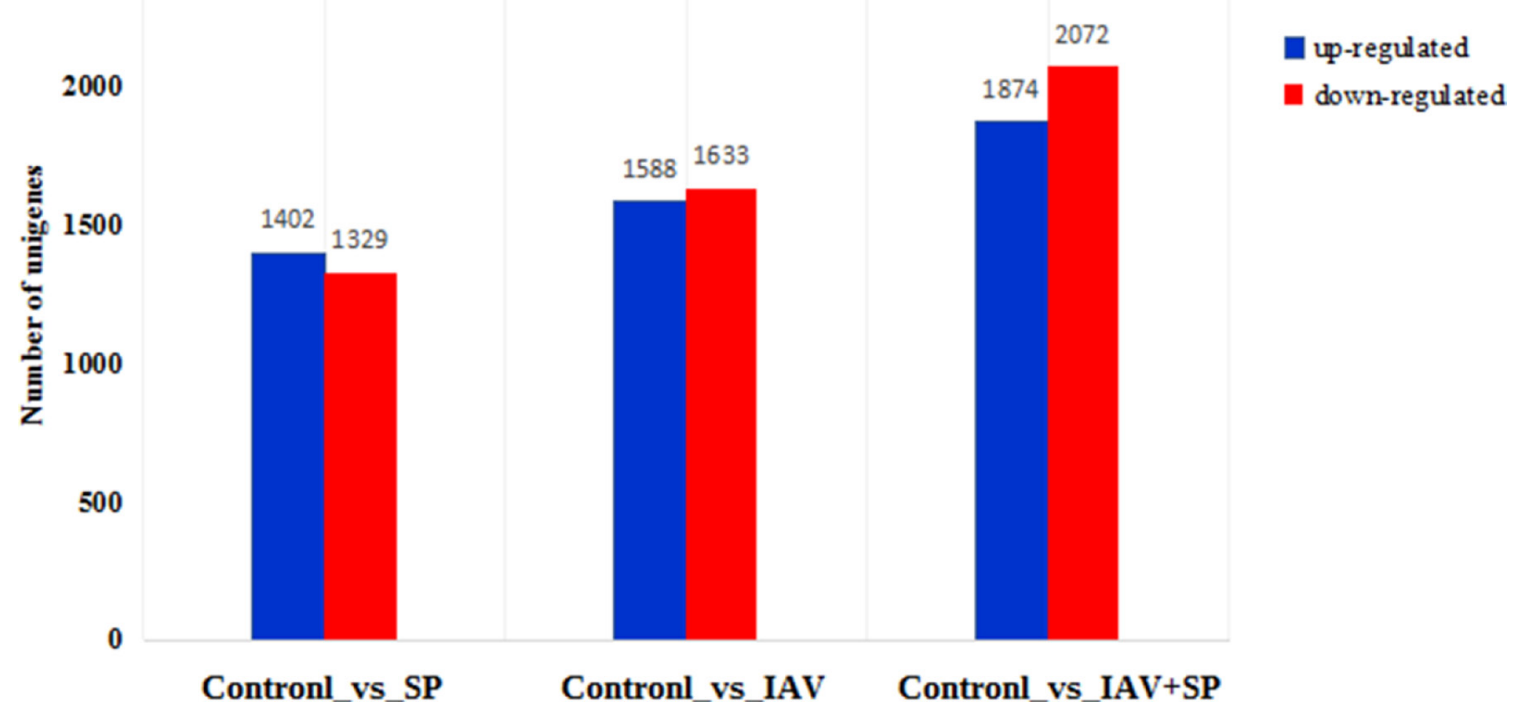

Figure 6: Number of DEGs in different groups. The abscissa represents the three groups; the ordinate represents the number of unigenes. 

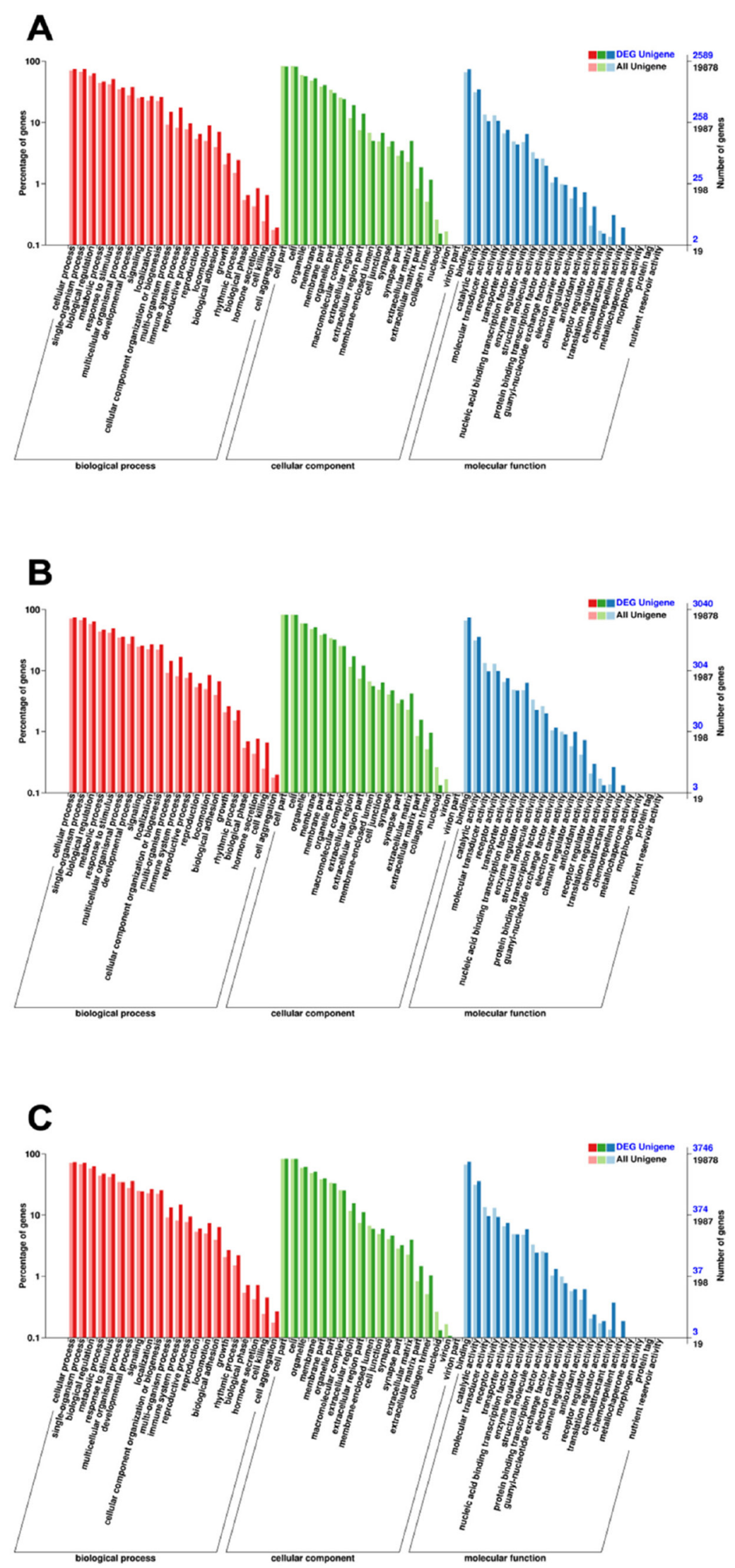

Figure 7: Categories of DEGs based on GO function. The results are summarized in three major categories: biological process, cellular component and molecular function. The abscissa represents the Categories in GO database; the ordinate represents the percentage of genes. (A) Categories of DEGs of SP. (B) Categories of DEGs of IAV. (C) Categories of DEGs of IAV+SP. 


\section{A}

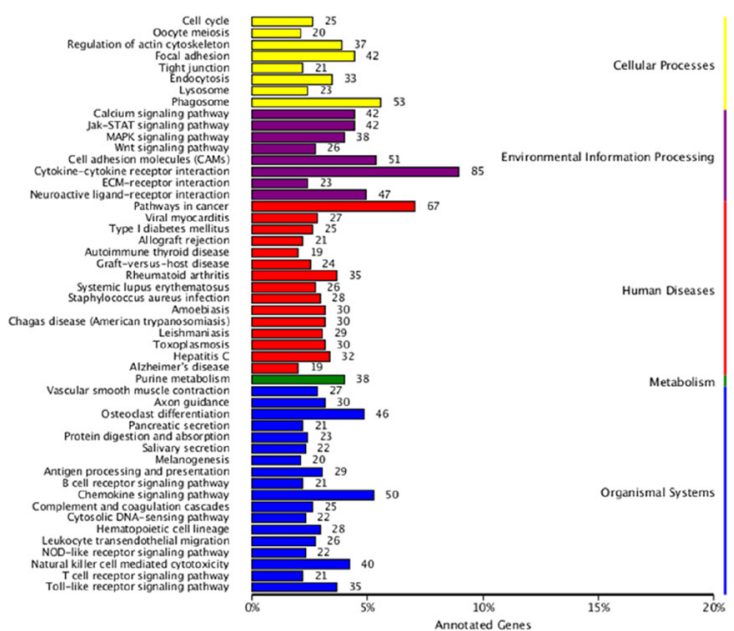

B

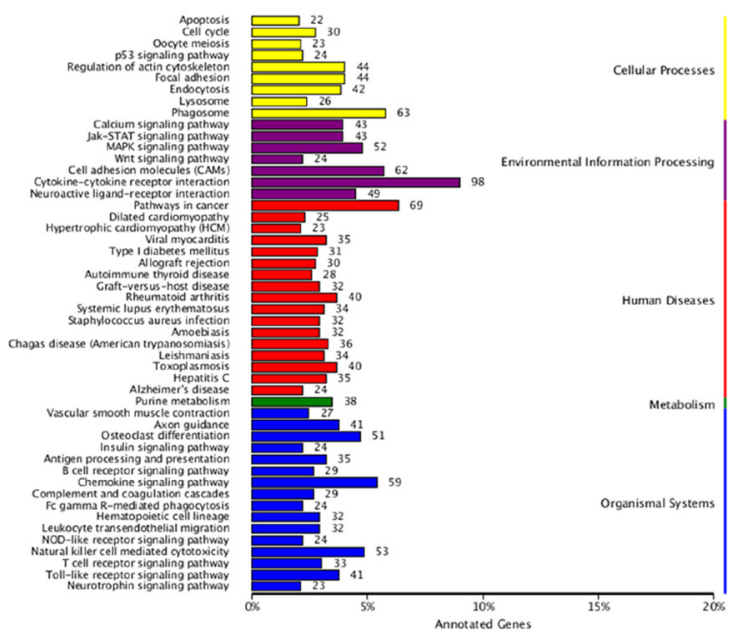

C

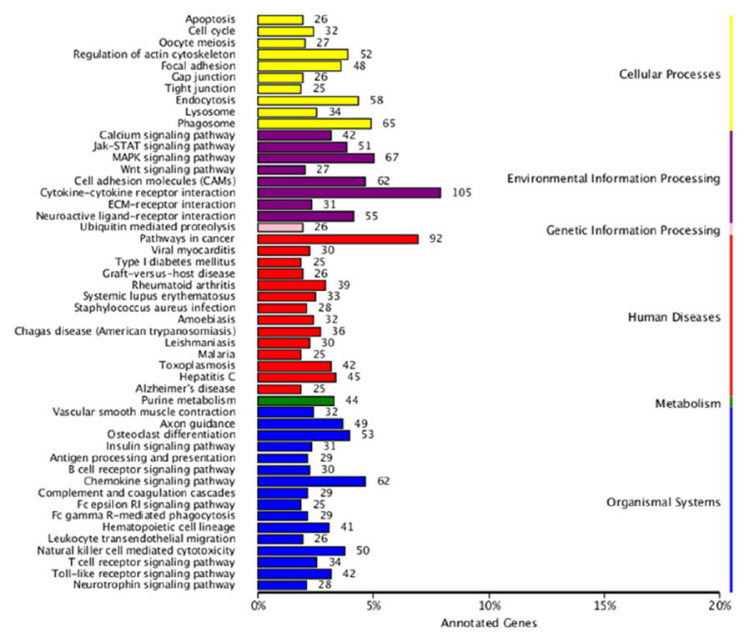

Figure 8: KEGG pathway classification of identified genes. The abscissa represents the annotated genes in KEGG database; the ordinate represents Categories in KEGG database. (A) KEGG pathway classification of SP. (B) KEGG pathway classification of IAV. (C) KEGG pathway classification of IAV+SP. 
the activation of caspase-3, caspase-6, and caspase- 7 . However, in the mitochondrial pathway, caspase- 8 could also cleave Bid (fold change of $\mathrm{Bid}: \mathrm{SP}=5.43, \mathrm{IAV}=5.93$, $\mathrm{IAV}+\mathrm{SP}=7.66)$ and translate activated $\mathrm{Bid}[26,27] . \mathrm{Bid}$ is a member of BH3-only protein that links death receptor crosslinking to pro-apoptotic events at mitochondria. In its uncleaved form, Bid is inactive as an apoptosis inducer. Following death receptor stimulation, Bid is cleaved by caspase- 8 , resulting in the generation of $\mathrm{tBid}$ [28]. Gene tBid is capable of inducing mitochondrial outer membrane permeabilization in cells. Its translocation from the cytoplasm to the mitochondria triggers the release of cytochrome c (fold change of cytochrome $c: \mathrm{SP}=1.80$, $\mathrm{IAV}=1.79, \mathrm{IAV}+\mathrm{SP}=2.36$ ) from the mitochondria, which in the cytoplasm triggers the cascade of caspase- 9 and caspase-3 activation, causing mitochondrial pathwayregulated apoptosis [26, 27, 29]. Gene caspase-12 (fold change of caspase-12: $\mathrm{SP}=1.61, \mathrm{IAV}=2.98, \mathrm{IAV}+\mathrm{SP}=3.13$ ) is cleaved and specifically activated only during ER stress, and is located on the cytoplasmic side of the ER $[30,31]$. It has been reported that caspase- 12 is the first ER associated member of the caspase family [32]. During ER stress-induced apoptosis cascade, activation of ER resident caspase-12 will further trigger the activation of cytoplasmic caspase-3(fold change of caspase-3: $\mathrm{SP}=1.80, \mathrm{IAV}=2.23, \mathrm{IAV}+\mathrm{SP}=3.06$ ) and, finally, trigger cellular apoptosis [33]. Caspases are a family of related proteases playing several important functions in apoptosis. They are essential to completion of apoptosis, and are activated in a cascade leading to rapid disablement of key cell structural proteins, chromatin condensation and DNA fragmentation, cell shrinkage and blebbing [34]. Both caspase-3 and caspase-7 (fold change of caspase-7: $\mathrm{SP}=1.77, \mathrm{IAV}=1.92, \mathrm{IAV}+\mathrm{SP}=2.16$ ) are effector caspases

Fold change of some genes between groups

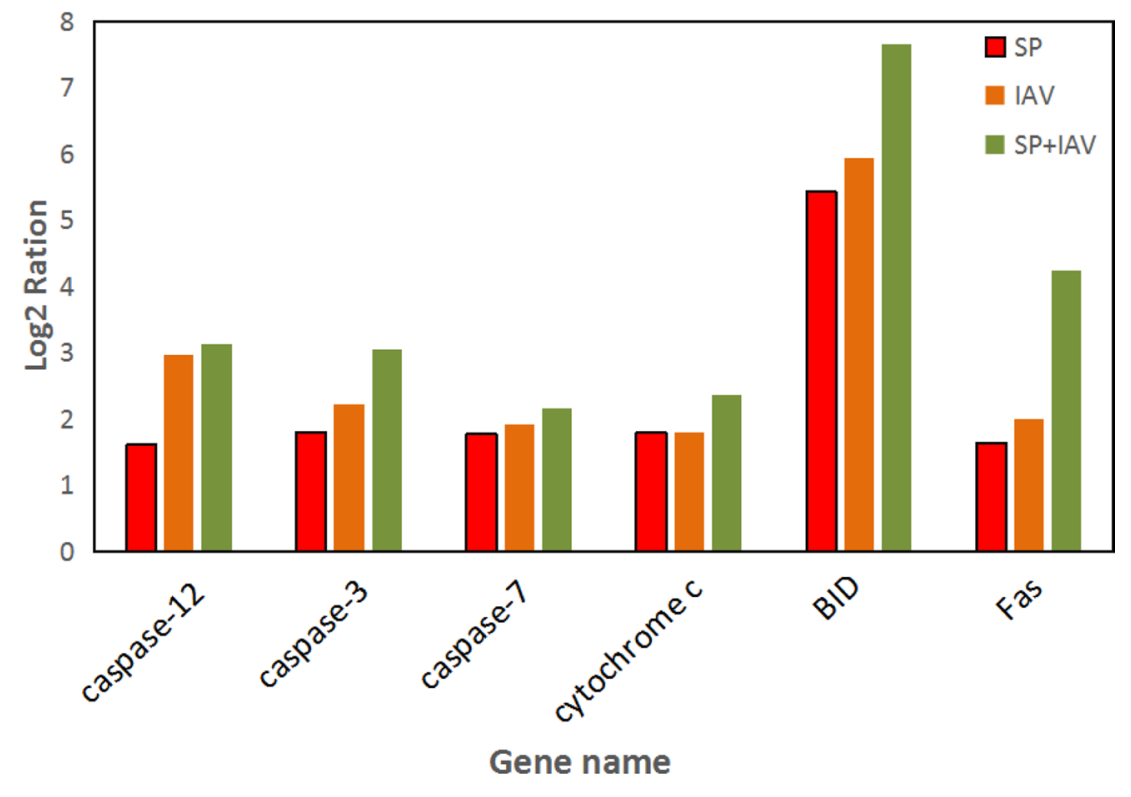

Figure 9: Fold change of some genes which are closely related to apoptosis.
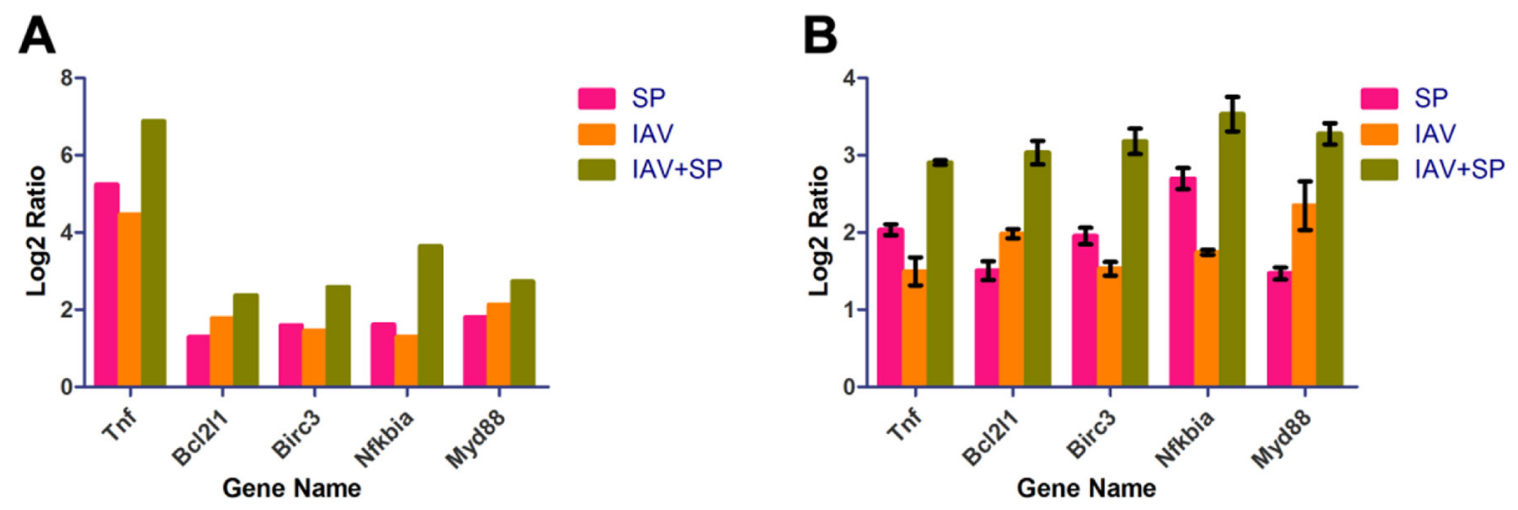

Figure 10: RT-PCR analysis of 5 randomly selected unigenes. (A) Gene expression data for DGE analysis. The fold changes of the genes were calculated as the log2 vaule of SP/Control, IAV/Control and IAV+SP/Control and shown on the y-axis. (B) The qRT-PCR analysis of gene expression data. Expression ratios of these genes in SP, IAV and IAV+SP were compared to Control, respectively. 
performing downstream execution steps of apoptosis by cleaving important cellular substrates [35]. Caspase-7 is highly related to Caspase-3, and these two caspases are activated during the death receptor pathway, mitochondrial pathway, and ER stress-mediated apoptosis [36, 37].

\section{CONCLUSIONS}

To our knowledge, our work represents the first report of the utilization of the next generation sequencing technique DGE for the study of apoptosis in mice when infected with SP, IAV or IAV+SP, with the motality rate was $20 \%, 35 \%, 100 \%$, respectively. When identified DEGs inducing apotosis involved in apoptosis pathway, the results demonstrated that the extent of fold change ranked the highest in IAV+SP group, followed by IAV group, then the SP group, which might be coincident with the trend of mortality rate.

\section{MATERIALS AND METHODS}

\section{Infection model and sample collection}

Influenza virus A/PR8 strain (H1N1) was grown in allantoic cavities of 10-day-old fertile chicken eggs for 3 days at $35^{\circ} \mathrm{C}$, and the produced virus was stored at $-80^{\circ} \mathrm{C}$ until infection experiments. Streptococcus pneumoniae (ATCC6303, a type 3 encapsulated strain, was grown on Columbia Agar plates supplemented with $5 \%$ (vol/vol) sheep blood. Female BALB/c ByJ mice (8-10 weeks old; Dashuo Company) were subjected to 4 treatments: PBS(Control), SP, IAV, and IAV+SP $(n=20$ for each group). SP with the concentration of $1.5 \times 105$ cfu and IAV of $1 \times 103$ TCID 50 were diluted in sterile PBS and administered intranasally in a volume of $100 \mathrm{~mL}$ (50 $\mathrm{mL} /$ nostril) to anesthetized mice. Mice were infected with either IAV or PBS and then challenged 5 days later with $S$. pneumoniae. Mice were monitored at least daily for illness and mortality and then euthanized at the seventh day after the first infection. Lung tissues were collected and placed into $500 \mathrm{~mL}$ of sterile PBS. Lung homogenates were used directly for bacterial cultures, or were spun at $10 \mathrm{~g}$ for $5 \mathrm{~min}$ to collect the supernatants for determination of virus titers. Lung tissues were also collected and stored in liquid nitrogen until used for other purposes. The animal experiments were approved by the Institutional Animal Care and Use Committee of Sichuan University.

\section{RNA isolation, preparation of library for DGE}

Following the manufacturer's protocol, total RNA of each sample was extracted by use of RNAiso Plus reagent (TaKaRa), then purified with absolute alcohol and treated with DNase I. The quality and quantity of both DNA

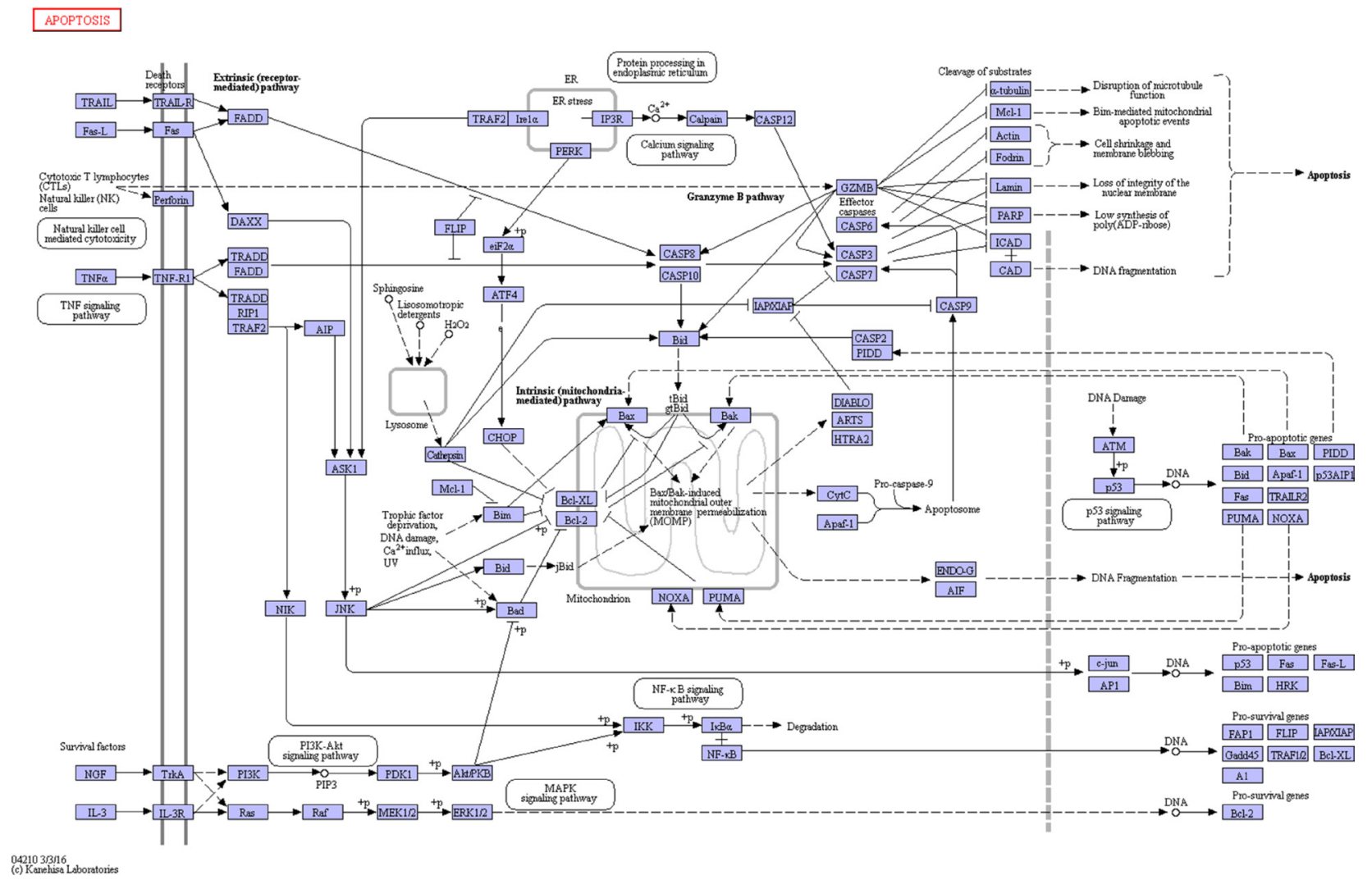

Figure 11: The KEGG pathway of apoptosis. 
Table 2: Primers used in qRT-PCR for DGE validation

\begin{tabular}{lcc}
\hline Gene & Forward primer $\left(\mathbf{5}^{\prime} \mathbf{- 3} \mathbf{)}\right.$ & Reverse primer $\mathbf{( \mathbf { 5 } ^ { \prime } \mathbf { - 3 } \mathbf { ) }}$ \\
\hline Tnf & TCTTCTCATTCCTGCTTGTGG & TACAGGCTTGTCACTCGAA \\
Bcl211 & TGGAAGAGAATCGCTAAACACA & TAGGAGAGAAAGTCGACCAC \\
Birc3 & AAAGGCCAAGAATTTGTCAGC & ATCATGACGACATCTTCCGAAC \\
Nfkbia & ACACGGAGTCAGAATTCACA & GAATCACCCCAGTAAAATGCC \\
Myd88 & AAACGCCGGAACTTTTCGATG & TCGCTTCTGTTGGACACCT \\
Actb & ATCCGTAAAGACCTCTATGCC & ACACAGAGTACTTGCGCTCA \\
\hline
\end{tabular}

and RNA were checked by gel electrophoresis and the DW-K5500 spectrophotometer (DRAWELL). By use of poly-T oligo attached magnetic beads (Invitrogen), approximately $10 \mu \mathrm{g}$ RNA of each sample was employed to separate Poly (A) mRNA. After purification, by use of divalent cations through elevated temperature, the mRNA was split into small fragments. According to the manufacturer's protocol of the mRNA-Seq sample preparation kit (Illumina), the RNA fragments were reverse-transcribed which were then used to create the cDNA library. In the single-end libraries, the average insert size was $180 \mathrm{bp}-200 \mathrm{bp}$.Then following the vendor's recommended protocol, we operated single-end sequencing $(50 \mathrm{bp})$ on the Illumina Hiseq2500. Raw data presented in this publication have been deposited in the NCBI Short Read Archive.

\section{Data processing and differentially expressed gene analysis}

In order to obtain clean reads, raw reads are processed by cutting off the 3 '-adaptor sequence and removing low-quality tags and tags that were too short or those with a single copy number. Then the clean reads were retained and mapped to the reference genome at $\mathrm{ftp}: / /$ ftp.ensembl.org/pub/release-78/fasta/mus musculus/. Data has been deposited to NCBI and included the accession number (SRP089851).

\section{Analyzing of differential gene expression}

Transcript level of each expressed gene was calculated and normalized to FPKM (the number of fragments per kilo base of exon per million fragments mapped). By using the rigorous algorithm method [38], the detection of differential gene expressions across samples was performed. DESeq software was applied to analyze differential gene expression in biological samples which was used to calculate and compare the differences of gene expression profile between virus or bacteriatreatment groups and control group. In our study, we had three biological repeats for each group and the correlation of the detected number of counts between parallel libraries was assessed statistically by calculating the Pearson correlation. The $P$ value threshold in multiple tests and analyses was determined by False discovery rate (FDR). Genes with FDR $<0.01$ and $\log 2$ ratio $\geq 1$ were considered the significant differentially expressed genes (DEGs). The possible functions of DEGs was determined by GO classification system. To further identify significantly enriched pathways, pathway enrichment analysis was performed by using the Kyoto Encyclopedia of Genes and Genomes (KEGG) database.

\section{Quantitative reverse transcription-polymerase chain reaction (qRT-PCR)}

Total RNA was extracted from lung tissues using RNAiso Plus reagent (TaKaRa) and reverse transcribed into complementary DNA (cDNA) using the PrimeScript ${ }^{\mathrm{TM}} \mathrm{RT}$ reagent Kit (TaKaRa) according to the manufacturer's recommendations. Real-time PCR was performed using SYBR Premix Ex Taq ${ }^{\mathrm{TM}}$ (TaKaRa) in the CFX96 ${ }^{\text {TM }}$ Real-Time System (Bio-Rad, USA). The conditions of thermal cycle were $95^{\circ} \mathrm{C}$ for denaturation in $3 \mathrm{~min}$, then 40 cycles with $95^{\circ} \mathrm{C}$ in $10 \mathrm{~s}$, followed by $58^{\circ} \mathrm{C}$ for annealing in $30 \mathrm{~s}$, and then an extension. Each gene was repeated in three times. The primers for qRT-PCR were listed in Table 2. Actin was used as a reference to eliminate bias among samples, and qRT-PCR results were converted and calculated via the $2-\Delta \Delta \mathrm{Ct}$ method [39].

\section{ACKNOWLEDGMENTS}

This work was financially supported by the National Science Foundation of China and the Natural Science Foundation of China (No. 30671964) and State Key Laboratory of Oral Diseases (No. SKLOD2015OF08).

\section{CONFLICTS OF INTEREST}

The authors of this paper have no conflicts of interest. 


\section{REFERENCES}

1. Muscedere J, Ofner M, Kumar A, Long J, Lamontagne F, Cook D, McGeer A, Chant C, Marshall J, Jouvet P, Fowler R; ICU-FLU Group and the Canadian Critical Care Trials Group. The occurrence and impact of bacterial organisms complicating critical care illness associated with 2009 influenza A (H1N1) infection. Chest. 2013; 144:39-47.

2. Morens DM, Taubenberger JK, Fauci AS. Predominant role of bacterial pneumonia as a cause of death in pandemic influenza: implications for pandemic influenza preparedness. J Infect Dis. 2008; 198:962-970.

3. McCullers JA. The co-pathogenesis of influenza viruses with bacteria in the lung. Nat Rev Microbiol. 2014; 12:252-262.

4. Webster RG, Govorkova EA. Continuing challenges in influenza. Ann Ny Acad Sci. 2014; 1323:115-139.

5. Kash JC, Tumpey TM, Proll SC, Carter V, Perwitasari O, Thomas MJ, Basler CF, Palese P, Taubenberger JK, GarcíaSastre A, Swayne DE, Katze MG. Genomic analysis of increased host immune and cell death responses induced by 1918 influenza virus. Nature. 2006; 443:578-581.

6. Kobasa D, Jones SM, Shinya K, Kash JC, Copps J, Ebihara H, Hatta Y, Kim JH, Halfmann P, Hatta M, Feldmann F, Alimonti JB, Fernando L, et al. Aberrant innate immune response in lethal infection of macaques with the 1918 influenza virus. Nature. 2007; 445:319-323.

7. Memoli MJ, Tumpey TM, Jagger BW, Dugan VG, Sheng ZM, Qi L, Kash JC, Taubenberger JK. An early 'classical'swine H1N1 influenza virus shows similar pathogenicity to the 1918 pandemic virus in ferrets and mice. Virology. 2009; 393:338-345.

8. Quantius J, Schmoldt C, Vazquez-Armendariz AI, Becker C, El Agha E, Wilhelm J, Morty RE, Vadás z I, Mayer K, Gattenloehner S, Fink L, Matrosovich M, Li X, et al. Influenza Virus infects epithelial stem/progenitor cells of the distal lung: impact on Fgfr2b-driven epithelial repair. PLoS Pathog. 2016; 12:e1005544.

9. Talmi-Frank D, Altboum Z, Solomonov I, Udi Y, Jaitin DA, Klepfish M, David E, Zhuravlev A, Keren-Shaul H, Winter DR, Gat-Viks I, Mandelboim M, Ziv T, et al. Extracellular Matrix Proteolysis by MT1-MMP Contributes to InfluenzaRelated Tissue Damage and Mortality. Cell Host Microbe. 2016; 20:458-470.

10. Maier BB, Hladik A, Lakovits K, Korosec A, Martins R, Kral JB, Mesteri I, Strobl B, Müller M, Kalinke U, Merad M, Knapp S. Type I interferon promotes alveolar epithelial type II cell survival during pulmonary Streptococcus pneumoniae infection and sterile lung injury in mice. Eur J Immunol. 2016; 46:2175-2186.

11. Xiao CW, Ji QA, Wei Q, Liu Y, Pan LJ, Bao G. Digital gene expression analysis of Microsporum canis exposed to berberine chloride. PLoS One. 2015; 10:e124265.
12. Walters KA, D'Agnillo F, Sheng ZM, Kindrachuk J, Schwartzman LM, Kuestner RE, Chertow DS, Golding BT, Taubenberger JK, Kash JC. 1918 pandemic influenza virus and Streptococcus pneumoniae co-infection results in activation of coagulation and widespread pulmonary thrombosis in mice and humans. J Pathol. 2016; 238:85-97.

13. McCullers JA, Rehg JE. Lethal synergism between influenza virus and Streptococcus pneumoniae: characterization of a mouse model and the role of platelet-activating factor receptor. J Infect Dis. 2002; 186:341-350.

14. Metzger DW, Sun K. Immune dysfunction and bacterial coinfections following influenza. J Immunol. 2013; 191:2047-2052.

15. Arora S, Lim W, Bist P, Perumalsamy R, Lukman HM, Li F, Welker LB, Yan B, Sethi G, Tambyah PA, Fairhurst AM, Alonso S, Lim LH. Influenza A virus enhances its propagation through the modulation of Annexin-A1 dependent endosomal trafficking and apoptosis. Cell Death Differ. 2016; 23:1243-1256.

16. El-Sayed I, Bassiouny K, Nokaly A, Abdelghani AS, Roshdy W. Influenza A Virus and Influenza B Virus Can Induce Apoptosis via Intrinsic or Extrinsic Pathways and Also via NF- $\kappa$ B in a Time and Dose Dependent Manner. Bioch Res Int. 2016; 2016:1738237.

17. Qin Z, Yang Y, Wang H, Luo J, Huang X, You J, Wang B, Li M. Role of Autophagy and Apoptosis in the Postinfluenza Bacterial Pneumonia, Biomed Res Int. 2016; 2016.

18. Molkentin JD. Calcineurin-NFAT signaling regulates the cardiac hypertrophic response in coordination with the MAPKs, Cardiovasc Res. 2004; 63:467-475.

19. Kitamura Y, Hashimoto S, Mizuta N, Kobayashi A, Kooguchi K, Fujiwara I, Nakajima H. Fas/FasL-dependent apoptosis of alveolar cells after lipopolysaccharideinduced lung injury in mice. Am J Resp Crit Care. 2001; 163:762-769.

20. Guinee D Jr, Brambilla E, Fleming M, Hayashi T, Rahn M, Koss M, Ferrans V, Travis W. The potential role of BAX and BCL-2 expression in diffuse alveolar damage. Am J Pathol. 1997; 151:99-1007.

21. Gill SE, Rohan M, Mehta S. Role of pulmonary microvascular endothelial cell apoptosis in murine sepsisinduced lung injury in vivo. Resp Res. 2015; 16:109.

22. Zuo H, Zeng L, Guo G, Zeng H. High-frequency oscillatory ventilation combined with partial liquid ventilation in experimental lung injury: effects on lung cell apoptosis. Wien Klin Wochenschr. 2015; 127:606-611.

23. Ghobrial IM, Witzig TE, Adjei AA. Targeting apoptosis pathways in cancer therapy. Ca-Cancer J Clin. 2005; 55:178-194.

24. Szegezdi E, Logue SE, Gorman AM, Samali A. Mediators of endoplasmic reticulum stress-induced apoptosis. Embo Rep. 2006; 7:880-885.

25. Ferreira CG, Span SW, Peters GJ, Kruyt FA, Giaccone G. Chemotherapy triggers apoptosis in a caspase-8-dependent 
and mitochondria-controlled manner in the non-small cell lung cancer cell line NCI-H460. Cancer Res. 2000; 60:7133-7141.

26. Sarosiek KA, Chi X, Bachman JA, Sims JJ, Montero J, Patel L, Flanagan A, Andrews DW, Sorger P, Letai A. BID preferentially activates BAK while BIM preferentially activates BAX, affecting chemotherapy response. Mol Cell. 2013; 51:751-765.

27. Li H, Zhu H, Xu CJ, Yuan J. Cleavage of BID by caspase 8 mediates the mitochondrial damage in the Fas pathway of apoptosis. Cell. 1998; 94:491-501.

28. Billen L, Shamas-Din A, Andrews D. Bid: a Bax-like BH3 protein, Oncogene. 2008; 27:S93-S104.

29. Gogvadze V, Orrenius S, Zhivotovsky B. Mitochondria as targets for cancer chemotherapy. Semin Cancer Biol. 2009; 19:57-66.

30. Nakagawa T, Zhu H, Morishima N, Li E, Xu J, Yankner BA, Yuan J. Caspase-12 mediates endoplasmic-reticulumspecific apoptosis and cytotoxicity by amyloid- $\beta$. Nature. 2000; 403:98-103.

31. Nakagawa T, Yuan J. Cross-talk between two cysteine protease families activation of caspase-12 by calpain in apoptosis. J Cell Biol. 2000; 150:887-894.

32. Sakurai M, Takahashi G, Abe K, Horinouchi T, Itoyama Y, Tabayashi K. Endoplasmic reticulum stress induced in motor neurons by transient spinal cord ischemia in rabbits. J Thorac Cardiov Sur. 2005; 130:640-645.

33. Hitomi J, Katayama T, Taniguchi M, Honda A, Imaizumi K, Tohyama M. Apoptosis induced by endoplasmic reticulum stress depends on activation of caspase- 3 via caspase- 12 . Neurosci Lett. 2004; 357:127-130.

34. Cryns V, Yuan J. Proteases to die for. Gene Dev. 1998; 12:1551-1570.

35. Shoja M, Reddy ND, Nayak PG, Srinivasan KK, Rao CM. Glycosmis pentaphylla (Retz.) DC arrests cell cycle and induces apoptosis via caspase-3/7 activation in breast cancer cells. J Ethnopharmacol. 2015; 168:50-60.

36. Wukirsari T, Nishiwaki H, Nishi K, Sugahara T, Akiyama K, Kishida T, Yamauchi S. Effect of the structure of dietary epoxylignan on its cytotoxic activity: relationship between the structure and the activity of 7, 7'-epoxylignan and the introduction of apoptosis by caspase $3 / 7$. Biosci Biotech Bioc. 2016; 80:669-675.

37. Médoc M, Dhilly M, Matesic L, Toutain J, KrauseHeuer AM, Delamare J, Fraser BH, Touzani O, Barré L, Greguric I, Sobrio F. In Vivo Evaluation of Radiofluorinated Caspase-3/7 Inhibitors as Radiotracers for Apoptosis Imaging and Comparison with [18F] ML-10 in a Stroke Model in the Rat. Mol Imaging Biol. 2016; 18:117-126.

38. Benjamini Y, Yekutieli D. The control of the false discovery rate in multiple testing under dependency. Ann Stat. 2001; 29:1165-1188.

39. Livak KJ, Schmittgen TD. Analysis of relative gene expression data using real-time quantitative PCR and the 2- $\Delta \Delta \mathrm{CT}$ method. Methods. 2001; 25:402-408. 